\title{
THE MOVEMENT, THE PHYSICAL EXERCISE, THE SPORTIVE GAME, THE TRADITIONAL DANCE,BASIC PARTS FOR MAINTAINING THE HUMAN BODY HEALTH
}

\author{
Lazăr TIPA \\ college teacher \\ Economic College ,'DimitrieCantemir" Suceava
}

\begin{abstract}
Key words: movement, physical exercise, sportive game, traditional dance,traditions, teacher, health.
\end{abstract}

\section{Introduction}

The human body movements, in our day by day life, conscious or/and subconscious, accompany us permanently and they are presented in various ways. The movement accompanies our life, life is accompanied the movement, healthy mind in a healthy body. "Menssana in corporesano".

Knowing the movement in its reality, you are aware of this and then the movement will be exploited with efficiency in your benefit. The aspects are available for all those interested in practising movement, theoretically, of performance, initiation, mental health, recreation, and of recovery. The outer movements are seen by some people as professional obligations, in the form of compulsory lessons of physical education or sportive activities, competitions, sportive games, traditional dances.

For others, it means recreation activities or substitutes, of psychomotor or neuropsychic recovery that are optionally. For most, the movement means fun, support, encouragement at sportive games, motion through traditional dance with emotional participation, regardless of age, gender and nationality. For other participants, more and more widespread, the physical exercises mean medicament movement, recognized seriously by world and national medical forums. Physical exercises represent basic movements in recovery treatment, maintenance, led by specialists.It can be said that the ways and conditions of practising physic exercise has been diversified a lot by the social interests, but especially by individual and group interests. In „Lumina” newspaper that appears under the aegis of Orthodox Patriarchate of Romania, movement and physical exercise appear in the form of prostrations, as necessary motion for body and soul health. The thirty daily prostrations are recommended to be made in the presence of the Most Holy image in the imagination of the executant. The prostrationsin spiritual life are divided in two categories of movements; short prostrations, with inclination and banding the body, followed by the floor touching with the fingertips and long prostrations, with staying on knees, followed by floor touching with executant's forehead. There are a lot of movements used and repeated by persons conscious and subconscious, in daily activities, only on the count of the same complex effort, psychologically and physically, as motions outside the social phenomenon, physical education and sport. Being part of most society, which influiencesit, physical education and sport due to movement has become a problem of social interest, generally, in continuous development. Physical education and sport is now all over the world and in Romania a big social problem, a dynamic and complex phenomenon with potentialforce and a social-educative considerable value, being efficient, cheap, attractive. In sportive games, the decisions with the analysis that preceded is the science of practising it, which can lead the athletes' executions to the final win. The choice of the winning alternative is sometimes more important than the right blocked execution of the opponent. The problem is that the sportsman must equally know more alternatives for every action apart, that in game time or during execution to choose the right moment. The satisfaction of practising sports and participating in competitions consists precisely in using all the abilities or winning, abilities that start with physical capacities, then with the psychological ones, followed by the physical ones, and ending with the pshychological ones based on feedback and successive decisions.

Physical exercise, practice, popular dance games represent like the daily life, a complex problem, driven permanently by successive decisions whose efficiency depends on the quality, opportunities, quantity of the available information received from the sport teacher, coach, instructor in popular dance, with all physical possibilities, physiological, physical performance of the performer (student, sportsman, junior, cadet, senior).In permanent education, the physical education teacher is engaged in a work of great delicacy and unique responsibility. The teacher of physical education and sport is a mentor of the younger generation, he is a living model because he exposes the physical exercises, not only by command and instructions, but also by execution of your own body. The physical teacher in the school he works makes a selection and he helps the students with special abilities based on sport where they have talents and a practical technique for team sports and individual ones and for popular dancing. The physical teacher organises competitions at school level in classes where they select students with talent and inclinations for each sport sector (male, female) with the right to participate in 
the competitions provided in the annual sports calendar between schools and high schools, municipal, national, international champions, and practising popular dance with participation in all school events, local, county and national. Everything depends on the school team from technical, tactical, phyisicalpoint of view, and on the students inclinations. In extracurricular activities, the physical education teacher directs pupils to practice traditional sports specific us named: "oină", "trântă", sport dance, team and individual sports, dance and folk songs from Bucovina, which are part of the artistic culture of the area.

Folk dances, customs and traditions are part of the artistic culture of the area they come from, such as in Bucovina. The popular dance around Suceava is characterized as a collective dance, a unitary execution of the movements, and which meets a great variety of rhythms and tempos.It is particularly nuanced and diversified, presenting within the Romanian cultural folklore a unitary and lovely repertory, with a mixture of a strong individual structure. It differs not only from region to region, but also from one locality to another, and even within the same locality, combining the elegance of female movements with the vitality and dynamics of masculine ones. The rhythm of Bucovina folk dances is complex and of a great inventiveness.

Dance is structured on a wide range of steps, from light and light to the well-intensified, with many spurs on the floor and in the air, stopped in strong and regular accents, which gives the dance a continuous, intermittent sound. This sensation creates a dance state that immerses you unceasingly to join the dancers. Small, light, detached from the ground footsteps, predominant in this part of the country, are generally structured in groups of 3 and 7 or groups of 4 beaten steps, on the rhythm, out of time and syncope steps with surprising individual nuances and group.They merge with small and large movements to the left and right, back and forth, with circular or semi-circle walks or pairs, which express an intense and vibrant emotional connection between performers, between themselves and the assistance they surround. There are also crossbows, top and foot heels, on the cushion and on the sole of the foot, as well as a wide range of arms position, both for group, pairs and individual dances. The technique of the movements is also very complex, with a high degree of difficulty. The elements of dance are unitarily structured in a variety of combinations that are made by combining all the elements of movement, characteristic is also the oscillation, swinging of the body with the slight movement of the head in the rhythm and the tempo of the music and the dance steps. That is why we can rightly say that the popular games in this area of Bucovina, generally the folk dances repertoire, is nothing lower, both in terms of the technical difficulty and dynamism, of the games in other regions of the country, alongside the most valuable and vigorous creations of the artistic culture in Bucovina and our country.

\section{“Omnia vincit labor improbus" \\ "Man only through work conquers" \\ “Citius, altius, fortius” \\ “Faster, higher, stronger"}

Finally, as a general conclusion, we must remember what the movement and the exercise practised and organized under the leadership of the specialized professor, contests and sports competitions, the folk dance specific to the Bucovina area with specific traditions under the guidance of the dance instructors, socialization and friendship of pupils and all participants, of all ages, learning new techniques, exchanging experience, learning habits and new traditions specific to the Bucovina arealead to the mobilization and recreation of the psychic, the disconnection of the individual stress and the practice after their acquisition, in the extracurricular program and in leisure time. It is only through work that man can get higher, faster and louder.

\section{Bibliography}

- Methodology and theory of physical education and sport Scientific research center, Bucharest.

- Popular traditions and customs in the Bucovina area Bucovina Cultural Center.

- "Lumina" Magazine of Romanian Orthodoxy. 